\title{
PEMETAAN POSISI ROBOT SOCCER MENGGUNAKAN GYRODOMETRY DAN TRIGONOMETRY UNTUK MEMPREDIKSI SUDUT TENDANGAN
}

\author{
Agus Khumaidi $^{1}$, Khoirun Nasikhin ${ }^{2}$, Projek Priyonggo ${ }^{3}$, Mardi Santoso ${ }^{4}$, Danis Bagus \\ Setiawan $^{5}$, Roudhotul Auliya Sa'adah ${ }^{6}$, Adi Wisnu Sahputra ${ }^{7}$ \\ 1,2,5,6,7 Teknik Kelistrikan Kapal, Prodi Teknik Otomasi \\ ${ }^{3,4}$ Teknik Permesinan Kapal, Prodi Teknik Permesinan kapal \\ Politeknik Perkapalan Negeri Surabaya \\ Kampus ITS Sukolilo Jl. Teknik Kimia, Keputih, Sukolilo, Surabaya, Kode Pos 60111 \\ Email $^{\varangle}$ :aguskhumaidi@ppns.ac.id
}

\begin{abstract}
The main robot that robots must have in wheeled balls is the ability to find balls, position in the goal, kick the ball and between robots with base station in the wheeled Indonesian Soccer Robot Contest (KRSBI). Wheeled type. KRSBI is one of the activities that are part of the Indonesian Robot Contest (KRI) as a venue for engineering and design competition in the field of robotics. One obstacle to the robot in the detection of the goal is still applying the Robust Algorithms method using only a camera, so that the search process is still relatively slow and kicking the ball is still often deviated from the opponent's goal. In this research, applying the Gyrodometry method in mapping the position of the robot in the field based on reading the sensor data of Rotary encoder and Gyroscope. Then the data will be sent from the microcontroller to the base station via PC and Router to be mapped. Whereas to detect the goal using Trigonometry calculation with the search of the goal based on the position of the robot's data on the Field with the opponent's goal point. The advantage of applying the Gyrodometry method in mapping the position of the robot in the field and Trigonometry calculations for goal detection can improve the efficiency of the robot to detect the goal with average speed (2.1s) and with an accuracy of 91.7\%.
\end{abstract}

Keywords: Gyrodometry, Trigonometry, Wheeled KRSBI, Kick Angle, Opposite Goal

\begin{abstract}
Abstrak
Kemampuan utama yang harus dimiliki robot sepak bola beroda adalah kemampuan menemukan bola, posisi gawang, menendang bola dan berkomunikasi antara robot dengan base station pada Kontes Robot Sepak Bola Indonesia (KRSBI) tipe beroda. KRSBI tipe beroda adalah salah satu kegiatan yang merupakan bagian dari Kontes Robot Indonesia (KRI) sebagai ajang kompetisi rancang bangun dan rekayasa dalam bidang robotika. Salah satu kendala pada robot Dalam pendeteksian gawang adalah masih menerapkan metode Robust Algorithms dengan hanya menggunakan kamera, sehingga proses pencarian masih terbilang lambat dan penendangan bola masih sering melenceng dari gawang lawan. Dalam Penelitian ini, menerapkan metode Gyrodometry dalam memetakan posisi robot dilapangan dengan berdasarkan pembacaan data sensor Rotary encoder dan Gyroscope. Kemudian data tersebut akan dikirim dari mikrokontroller menuju base station melalui PC dan Router untuk dipetakan. Sedangkan untuk mendeteksi gawang menggunakan perhitungan Trigonometri dengan pencarian gawang berdasarkan data posisi titik robot pada Lapangan dengan titik gawang lawan. Keuntungan dalam menerapkan metode Gyrodometry dalam memetakan posisi robot dilapangan dan perhitungan Trigonometri untuk mendeteksi gawang dapat meningkatkan efisiensi robot untuk mendeteksi gawang dengan kecepatan Rata-rata (2.1s) serta dengan akurasi $91.7 \%$.
\end{abstract}

Kata kunci: Gyrodometry, Trigonometri, KRSBI Beroda, Sudut Tendangan, Gawang Lawan

\section{Pendahuluan}

Kontes Robot Indonesia (KRI) adalah salah satu kompetisi yang di selenggarakan oleh RISTEDIKTI yang berfokus untuk rancang bangun atau rekayasa dalam bidang robotika. Salah satu kegiatannya yaitu Kontes Robot Sepak bola Indonesia Beroda (KRSBI Beroda). KRSBI yang diselenggarakan di 
indonesia berdasarkan aturan internasional yang berlaku di RoboCup Middle Size League (MSL), dengan menyesuaikan kondisi di Indonesia [1].

Ketidakakuratan robot dalam melakukan penembakan bola kedalam gawang lawan bukan hanya disebabkan pendektesian gawang oleh kamera, tetapi juga karena robot tidak mengetahui posisi dimana titik robot itu sendiri dan titik gawang lawan atau bahkan tidak memprediksi sudut tendangan bola sama sekali. Pada penggunaan metode Robust Algorithm dalam mendeteksi gawang dengan memanfaatkan area tepi lapangan mampu bekerja dengan baik serta memiliki tingkat akurasi yang tinggi. Namun untuk mendapatkan hasil deteksi yang maksimal perlu dilakukan kalibrasi yang tepat dan jelas sehingga warna putih lain yang berada di atas tepi lapangan tidak dapat terdeteksi serta proses tersebut akan menyebabkan alokasi CPU menjadi besar yaitu $81,8 \%$ [2].

Penerapan metode Gyrodometry dalam pemetaan posisi dengan tujuan agar robot mengetahui posisi yang tepat, sedangkan untuk menentukan sudut tendangan bola terhadap gawang lawan robot akan mendeteksi posisi (titik robot itu sendiri) dan gawang lawan (titik tengah gawang) serta menentukan sudut antara robot dengan gawang lawan dengan menggunakan perhitungan Trigonometri. Robot dengan pemetaan posisi dan prediksi sudut tendangan ini memudahkan dalam pencarian gawang lawan sehingga robot dapat menendang bola secara akurat. Bukan hanya itu, efesiensi waktu yang akan digunakan akan semakin tinggi dan proses pencarian gawang semakin cepat sehingga meningkatkan kemungkinan terjadainya Gol kedalam gawang lawan. Serta dalam melakukan positionning yang diperintah oleh base station akan meningkatkan kinerja dan keakuratan pada robot [3].

\section{Metode Penelitian}

Adapun Langkah yang dilakukan dalam penelitian ini meliputi perancangan sistem robot, pembuatan mekanik dan software, dan pengujian sistem robot pada posisi dan sudut tendangan terhadap gawang lawan sehingga akan diperoleh nilai yang terbaik.

Kalibrasi titik x dan y sama dengan nol dan $\theta=90^{\circ}$ robot ditempatkan disebelah pojok kiri bawah dan dihadapkan pada sumbu y seperti Gambar 1(a). Setelah kalibrasi, kemudian sensor rotary encoder dan gyroscope dinyalakan untuk pembacaan sensor. Pada saat yang bersamaan data yang dibaca akan dikonversi untuk estimasi posisi relative dari robot, estimasi ini menggunakan perhitungan jumlah pulsa yang dihasilkan oleh sensor rotary encoder setiap satuan ukuran yang kemudian dikonvolusikan menjadi sebuah millimeter dengan persamaan (1) dan (2).

$$
\begin{aligned}
& \mathrm{K}_{\text {roda }}=2 \pi r \\
& \text { Pulsa }_{\text {per }_{\mathrm{mm}}}=\frac{\text { resolusi }_{\text {enc }}}{\mathrm{K}_{\text {roda }}}
\end{aligned}
$$

Dimana:

$\mathrm{K}_{\text {roda }} \quad$ : Keliling Roda Omni

Pulsa $_{\text {per }_{\mathrm{mm}}}$ : konversi pulsa ke

milimeter

r $\quad$ : jari - jari roda

Setelah dikonversi selanjutnya menghitung nilai $\mathrm{x}$ dan $\mathrm{y}$ robot yang dilengkapi dengan 3 buah sensor rotary encoder dipasang masing-masing 120 derajat seperti pada Gambar 1(b). Maka berlaku persamaan (3) sampai (5).

$$
\begin{aligned}
V y & =S_{1} \operatorname{Cos}(\varnothing)-S_{2} \operatorname{Cos}(\varnothing) \\
V x & =S_{3}-S_{1} \operatorname{Sin}(\emptyset)-S_{2} \operatorname{Sin}(\varnothing) \\
V \theta & =\frac{S_{1}}{L}+\frac{S_{2}}{L}+\frac{S_{3}}{L}
\end{aligned}
$$

Dimana, 
$S(1,2,3)$ : Jarak tempuh masing-masing roda $(\mathrm{mm})$

Sedangkan untuk mendapatkan koordinat kartesian dari lapangan perlu ditransformasikan dengan menggunakan matriks persamaan (6).

$$
\left[\begin{array}{c}
Y \text { pos } \\
X \text { pos } \\
\theta
\end{array}\right]=\left[\begin{array}{ccc}
\cos (v \theta) & -\sin (v \theta) & 0 \\
\sin (v \theta) & \cos (v \theta) & 0 \\
0 & 0 & 1
\end{array}\right]\left[\begin{array}{c}
V y \\
V x \\
V \theta
\end{array}\right]
$$

Dimana,

Ypos $=$ posisi robot y dalam koordinat kartesian (mm)

$X p o s=$ posisi robot $\mathrm{x}$ dalam koordinat kartesian (mm)

$\theta \quad=$ arah hadap robot

\section{Algoritma Penentuan Sudut Tendangan}

Robot diprogram untuk mencari titik $(\mathrm{x}, \mathrm{y})$ dimana titik tersebut didapat dari data Rotary encoder dan $\theta$ robot didapat dari pemfilteran antara data rotary encoder dengan data dari sensor gyroscope. Gambar 2 merupakan ilustrasi pencarian sudut gawang. Selanjutnya menghitung selisih antara titik $\mathrm{x}$ robot dengan panjang $x$ lapangan yang dibagi 2 yang disebut $\mathrm{dx}$, sedangkan untuk mencari dy yaitu menghitung selisih antara panjang total y dengan titik y robot. Kemudian untuk mencari $r$ menggunakan teorema phytagoras dengan persamaan (7), (8), dan (9).

$$
\begin{aligned}
& \mathrm{dx}=\left(\mathrm{x}_{\text {total }} / 2\right)-(\mathrm{x} \text { robot }) \\
& \mathrm{dy}=\left(\mathrm{y}_{\text {total }}\right)-(\mathrm{y} \text { robot }) \\
& \mathrm{r}=\sqrt{d x^{2}+d y^{2}}
\end{aligned}
$$

\section{Dengan :}

$\mathrm{dx}=$ panjang sisi samping segitiga siku-siku

dy $=$ panjang sisi depan segitiga siku-siku

$\mathrm{r}=$ panjang sisi miring segitiga siku-siku
Dilanjutkan menghitung $d \theta$ dengan trigonometri berdasarkan segitiga sikusiku.

- Apabila x 500 maka $d \theta=90^{\circ}$.

- Apabila $0>=x<500$ maka perhitungan berdasarkan persamaan (9) dan (10).

$$
\begin{aligned}
& \operatorname{Sin}(\theta)=\frac{d y}{r} \\
& d \theta=\arcsin (\sin \theta) \\
& \text { - Apabila } 500>\mathrm{x}<=1000 \text { maka } \\
& \text { perhitungan berdasarkan persamaan (9) } \\
& \text { dan (11). }
\end{aligned}
$$

$$
d \theta=\left(180^{\circ}\right)-(\arcsin (\sin \theta))
$$

Setelah mendapat nilai sudut $d \theta$ kemudian data tersebut akan diolah microcontroller untuk mengontrol berputar menuju $d \theta$. Setelah microcontroller mendapatkan nilai sudut gawang $(d \theta)$ maka selanjutnya adalah mengontrol posisi awal robot $\theta$ menuju $d \theta$. Untuk mendapatkan hasil maksimal digunakan metode control dengan PID. Gambar 3 menunjukkan blok diagram dari sistem yang digunakan secara umum yaitu menggabungkan karakteristik dari kedua sensor yang digunakan rotary encoder dan gyroscope dimana data arah hadap $(\theta)$ dari kedua sensor tersebut digabungkan untuk mendapatkan data arah hadap robot yang akurat menggunakan metode complementary filter.

\section{Hasil Dan Pembahasan}

Robot diberikan pulsa masukan berupa kecepatan kearah sumbu $\mathrm{X}$ atau sumbu $\mathrm{Y}$ atau keduanya, maka selanjutnya robot akan bergerak dengan delay yang sudah ditentukan dan robot akan berhenti. Hasil pengujian ditunjukkan pada Tabel 1 . Pengujian gyrodometry perubahan posisi dilakukan untuk mengetahui apakah algoritma yang disusun untuk mengetahui perpindahan yang telah dicapai oleh robot 
dan di ketahui nilai error antara perpindahan yang telah dicapai robot secara aktual dengan nilai perpindahan robot yang dibaca oleh sensor yang ditampilkan pada Tabel 2. Tabel 3 merupakan hasil pengujian arah hadap robot yang dihasilkan dari rumus odometry 3 omni wheels, sudut arah hadap robot ini dipengaruhi oleh jarak antara pusat robot ke pusat roda omni. Pada Gambar 4, menunjukkan grafik penggabungan karakteristik dari kedua sensor yang digunakan antara rotary encoder dan gyroscope dimana data arah hadap $(\theta)$ dari kedua sensor tersebut digabungkan untuk mendapatkan data arah hadap robot yang akurat. Selanjutnya, pengujian trigonometri untuk mengetahui seberapa cepat robot dapat merespon pencarian gawang lawan dan juga seberapa cepat robot dapat bergerak menghadap ke gawang lawan. Hasil pengujian ini ditunjukkan pada Tabel 4. konstanta set point gawang lawan $=90^{\circ}$, titik $x=500 \mathrm{~cm}$, dan $y=$ $1200 \mathrm{~cm}$. dengan asumsi robot sudah mendapatkan bola dan tanpa penjaga gawang, warna merah menandakan tidak gol.

\section{Kesimpulan}

Setelah melalui beberapa proses perencanaan, pembuatan dan pengujian dapat diambil kesimpulan sebagai berikut.

1. Robot sudah mampu menerapkan gyrodometry untuk optimasi performa dalam memetakan posisi dan melakukan positioning dengan error rata-rata $\mathrm{x}=2.8 \mathrm{~cm}, \mathrm{y}=2.4 \mathrm{~cm}$, dan $\theta=0.66^{\circ}$.

2. Robot sudah mampu menerapkan perhitungan trigonometri dalam mendeteksi sudut robot terhadap gawang lawan, tetapi jika y robot > $800 \mathrm{~cm}$ dari gawang lawan maka error terjadinya gol akan lebih besar.
3. Waktu yang diperlukan robot untuk mendeteksi sudut terhadap gawang lawan lebih cepat dengan rata-rata 2.10 s dan $91.7 \%$ terjadi gol pada gawang lawan.

\section{Daftar Pustaka}

[1]. Ristekdikti. (2018). Buku Panduan Kontes Robot Sepak Bola Indonesia Beroda (KRSBI Beroda) 2018. Jakarta: Ristekdikti.

[2]. Arinata, G. P. (2018). Optimasi Deteksi Bola Dan Gawang pada robot sepak bola beroda menggunakan Region-Based Segmentation dan Robust Algorithm. Surabaya: Politeknik Perkapalan Negeri Surabaya.

[3]. Affandi, I., Sulistijo, I. A., \& Ardilla, F. (2014). Kontrol Posisi Robot Omni-Directional Menggunakan Metode Gyrodometry. Yogyakarta: The 2nd Symposium o $\mathrm{n}$ Robot Soccer Competition.

[4]. Borenstein, J., \& Feng, L. (1996). Gyrodometry: A New Method for Combining Data from Gyros and Odometry in Mobile robots. Minneapolis: IEEE International on Robotics and Automation.

[5]. Bramanta, A., Virgono, A., \& Erfa Saputra, R. (2017). Control System Implementation and Analysis for omniwheel Vehicle. The 2017 International Conference on Control, Electronics, Renewable Energy and Communication (ICCEREC). Bandung.

[6]. Kurnianto Wibowo, I., Mobed Bachtiar, M., \& Sena Bayu D, B. (2018). Penentuan Posisi Robot Menggunakan Odometry Omniwheel. The 6th Indonesian Symposium on Robotic Systema and Control (ISRSC). Yogyakarta. 


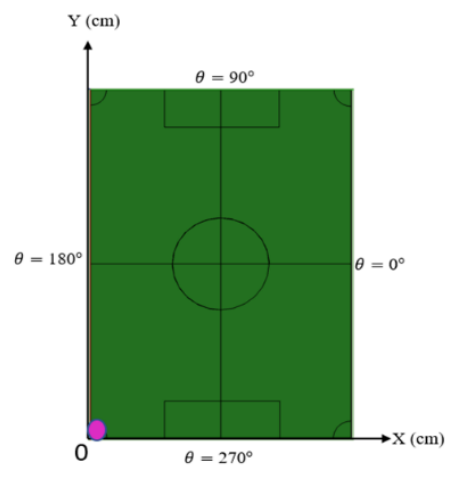

(a)

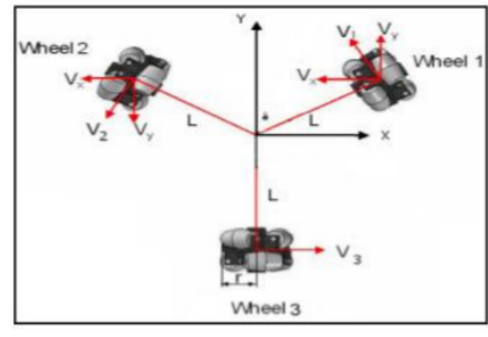

(b)

Gambar 3. Ilustrasi sumbu x dan y pada lapangan (a), Representasi penempatan Rotary encoder (b)

Keterangan :

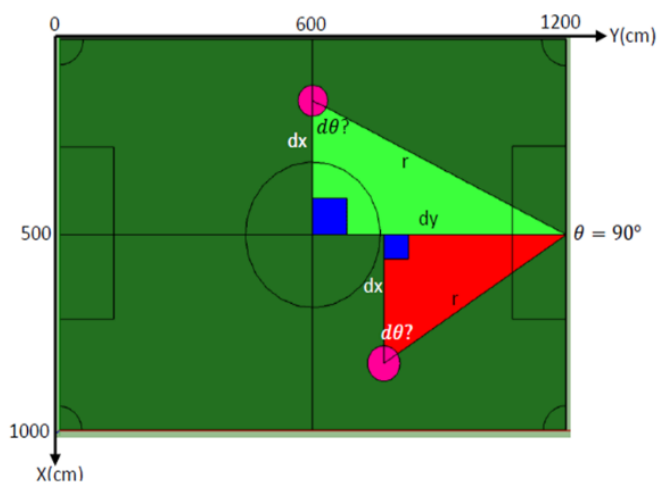

Gambar 2. Ilustrasi pencarian sudut gawang

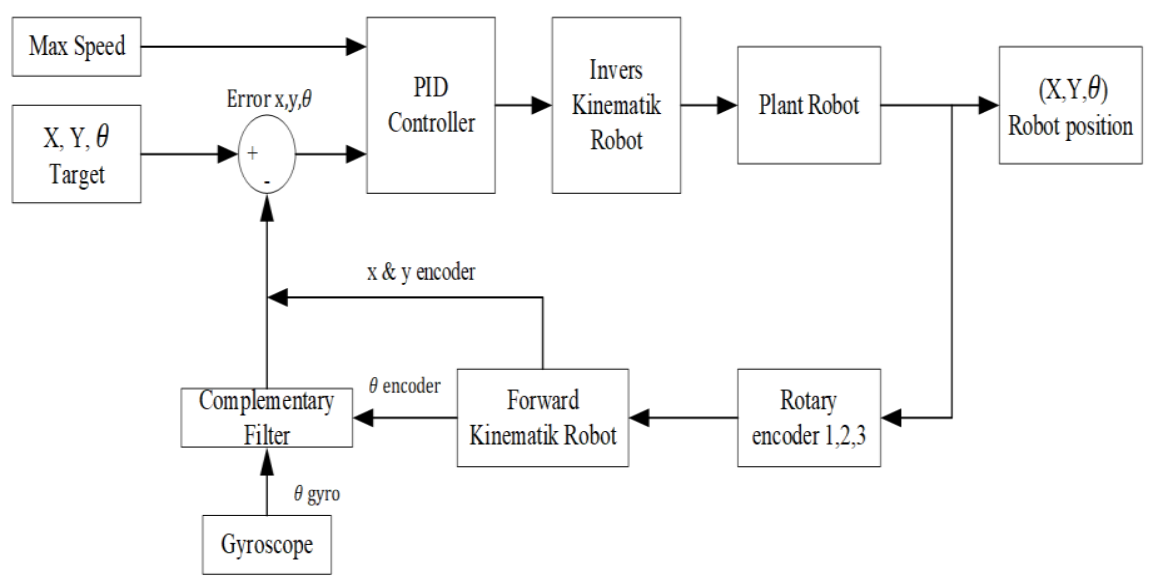

Gambar 1. Diagram blok sistem kontrol Robot 
Agus Khumaidi, dkk., Pemetaan Posisi...

Tabel 1. Hasil Pengujian Pergerakan Robot

\begin{tabular}{|c|c|c|c|c|c|c|c|c|c|c|}
\hline No & $\mathbf{V x}$ & $\mathbf{V y}$ & $\mathbf{V \theta}$ & V1 & $\mathbf{V} 2$ & V3 & V4 & $\begin{array}{c}\text { Arah } \\
\text { Sudut } \\
\left(^{\circ}\right)\end{array}$ & $\begin{array}{c}\text { Sudut } \\
\text { Real } \\
\left(^{\circ}\right)\end{array}$ & $\begin{array}{c}\text { Error } \\
(\%)\end{array}$ \\
\hline 1 & 0 & 1000 & 0 & 707.10 & -707.10 & -719.33 & 694.65 & 0 & 9.45 & 2.63 \\
\hline 2 & 1000 & 1000 & 0 & 1.13 & $\begin{array}{c}- \\
1414.21\end{array}$ & -24.68 & 1413.99 & 45 & 56.31 & 3.14 \\
\hline 3 & 1000 & 0 & 0 & -707.10 & -707.10 & 694.65 & 719.33 & 90 & 102.12 & 3.36 \\
\hline \multicolumn{10}{|c|}{ Rata-rata error } & 3.04 \\
\hline
\end{tabular}

Tabel 2. Hasil Pengujian Gyrodometry Perubahan Posisi

\begin{tabular}{cccccccccc}
\hline \multirow{2}{*}{ No } & \multicolumn{3}{c}{ Target position } & \multicolumn{3}{c}{ Pulse Encoder } & \multicolumn{3}{c}{ Real position } \\
\cline { 2 - 10 } & $\mathbf{X}(\mathbf{c m})$ & $\mathbf{Y}(\mathbf{c m})$ & $\emptyset\left(^{\circ}\right)$ & $\mathbf{1}$ & $\mathbf{2}$ & $\mathbf{3}$ & $\mathbf{X}(\mathbf{c m})$ & $\mathbf{Y}(\mathbf{c m})$ & $\emptyset\left(^{\circ}\right)$ \\
\hline $\mathbf{1}$ & 0 & 200 & 0 & -7496 & 7491 & 98 & 0.9 & 203.9 & 0 \\
\hline $\mathbf{2}$ & 200 & 0 & 0 & -4198 & -4376 & 8764 & 205.0 & -1.4 & -2 \\
\hline $\mathbf{3}$ & 200 & 200 & 0 & -11725 & 3297 & 8531 & 202.5 & 202.1 & 0 \\
\hline \multicolumn{4}{c}{ Rata-rata Error } & & & $\mathbf{2 . 8}$ & $\mathbf{2 . 4 6}$ & $\mathbf{0 . 6 6}$ \\
\hline
\end{tabular}

Tabel 3. Hasil Pengujian Odometry Arah Hadap Robot

\begin{tabular}{cccc}
\hline No & $\begin{array}{c}\text { Sudut } \\
\text { Target }\end{array}$ & Sudut Real & Error Sudut \\
\hline $\mathbf{1}$ & $0^{\circ}$ & $0^{\circ}$ & $0 \%$ \\
\hline $\mathbf{2}$ & $40^{\circ}$ & $41^{\circ}$ & $2.5 \%$ \\
\hline $\mathbf{3}$ & $80^{\circ}$ & $80^{\circ}$ & $0 \%$ \\
\hline $\mathbf{4}$ & $120^{\circ}$ & $122^{\circ}$ & $1.66 \%$ \\
\hline $\mathbf{5}$ & $160^{\circ}$ & $159^{\circ}$ & $0.625 \%$ \\
\hline
\end{tabular}

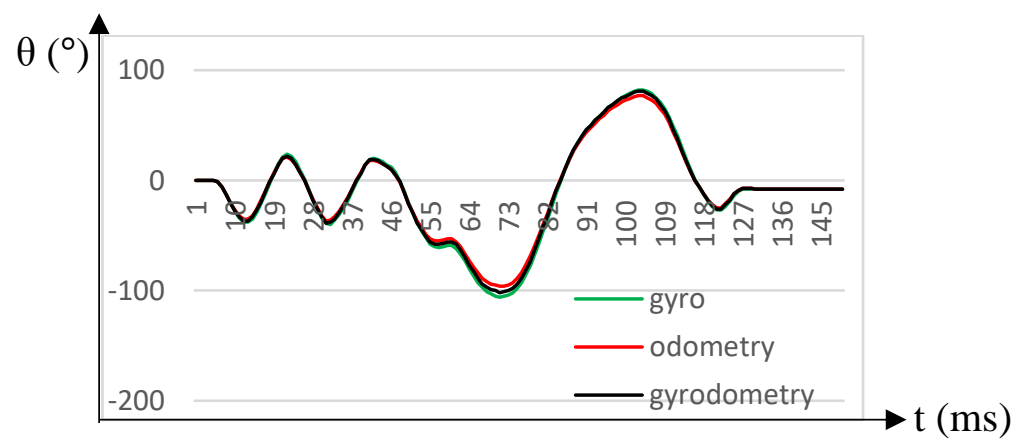

Gambar 4. Grafik hasil pengujian Gyrodometry 
POLITEKNOLOGI VOL. 19 NO. 3 SEPTEMBER 2020

Tabel 4. Hasil Pengujian Trigonometri

\begin{tabular}{|c|c|c|c|c|c|}
\hline \multirow[b]{2}{*}{ NO } & \multicolumn{2}{|c|}{$\begin{array}{c}\text { Titik } \\
\text { Robot }(\mathbf{c m}) \\
\end{array}$} & \multicolumn{3}{|c|}{$\begin{array}{c}\text { waktu yang dibutuhkan } \\
\text { (s) }\end{array}$} \\
\hline & $\begin{array}{c}\mathbf{X} \\
(\mathbf{c m})\end{array}$ & $\begin{array}{c}\mathbf{Y} \\
(\mathbf{c m})\end{array}$ & $\begin{array}{l}\text { Sudut } \\
\text { robot }= \\
0^{0}\end{array}$ & $\begin{array}{l}\text { Sudut } \\
\text { robot }= \\
270^{\circ}\end{array}$ & $\begin{array}{l}\text { Sudut } \\
\text { robot = } \\
180^{\circ}\end{array}$ \\
\hline 1 & 350 & 350 & 1.45 & 1.83 & 1.56 \\
\hline 2 & 500 & 350 & 0.77 & 1.87 & 1.74 \\
\hline 3 & 650 & 350 & 1.41 & 2.06 & 1.49 \\
\hline 4 & 350 & 600 & 1.42 & 1.53 & 1.24 \\
\hline 5 & 500 & 600 & 1.25 & 1.15 & 1.09 \\
\hline 6 & 650 & 600 & 1.37 & 2.37 & 1.14 \\
\hline 7 & 350 & 800 & 1.30 & 1.40 & 1.03 \\
\hline 8 & 500 & 800 & 0.71 & 2.24 & 1.18 \\
\hline 9 & 650 & 800 & 1.32 & 2.46 & 0.90 \\
\hline 10 & 350 & 1000 & 3.73 & 5.88 & 3.80 \\
\hline 11 & 500 & 1000 & 2.30 & 4.40 & 2.93 \\
\hline 12 & 650 & 1000 & 3.78 & 6.01 & 3.60 \\
\hline \multirow{2}{*}{\multicolumn{3}{|c|}{ Rata-rata }} & 1.73 & 2.76 & 1.80 \\
\hline & & & \multicolumn{3}{|c|}{2.10} \\
\hline \multicolumn{3}{|c|}{ Goal } & \multicolumn{3}{|c|}{$91.7 \%$} \\
\hline
\end{tabular}

